of the ease. From the period mentioned its progress was very rapid, and in about two months it was necessary to perform paracentesis. The usual relief to the embarrassed organs of the thorax followed this operation, but the patient suffered considerably from abdominal pain for about a week afterwards. The fluid reaccumulated with great rapidity, and in six weeks or thereabouts there was again necessity to tap him, but the performance of the operation was not desired by his relatives, and did not, in fact, from his then condition, seem advisable. Soon afterwards he was seized with hrematemesis and died within a few days, death being preceded by an unusually long comatose stage-about seventy-two hours.

The post-mortem examination extended only to the abdominal cavity, permission to make a limited dissection only having been received. The liver, which was moderately contracted, presented the appearance of an ideal specimen of the hobnail variety of cirrhosis. The surface tumours resembled unripe cherries in size and appearance, and on the surface of some of them tortuous bloodvessels were to be seen. On a deep section being made, the division of the organ into spherical lobules, corresponding in size to those visible externally, was well observed. The surface was free from adhesions or other evidence of a peripheral inflammation. Sections under the microscope corresponded in appearance with the illustrations (after Dreschfeld and Young) of this disease in the New Sydenham Society's Atlas of Pathology. The spleen was enlarged, but only to a moderate extent. There was no sclerosis of its tissue, but this was somewhat more soft and friable than normal.

Remarks.-The foregoing case would appear to offer for consideration the following points of special interestnamely: 1 . The age of the patient. 2. The fact of his having been the third successive member of the same family who died in adolescence from the disease in question. 3 . The abnormal condition of the blood. I am aware that there is nothing extraordinary in the age "of the patient, but still it is decidedly exceptional. It may be considered, further, in connexion with the second point, which seems to me to be a unique experience, and more especially when it can be alleged with absolute certainty that in none of the three cases was there a suspicion of any of those agencies with which we are accustomed to associate cirrhosis of the liver. It is to be recorded, however, in regard to one of those agencies, that there was a history of long-continued alcoholic excess on the part of the father of the children. It is true that his death, which took place about five years ago, was not due to liver disease, but to cerebral apoplexy; there is, however, a fair presumpision that in his case there were degenerative hepatic changes due to the cause under observation. Did he then transmit to his offspring a diathesis hereditarily determining cirrhotic atrophy of the liver? That seems a fair inference from the detailed medical histories of the children, but in relation to the broad question of pathology the question is a new one, to me at any rate; but if it be possible to answer it in the affirmative from the foregoing experience, it will serve to explain some of those anomalous cases of this disease in regard to which Frerichs has written the following pregnant sentence: "There are undoubtedly causes of cirrhosis with which as yet we are totally unacquainted." There is next to be considered the question of the condition of the blood, and under this heading it is perhaps necessary to allude to the diagnosis of the case. It may be said that the patient was the subject of two intercurrent diseases-viz., cirrhosis of the liver and splenic leucocythemia. Such an impression was entertained during the clinical progress of the case, but obviously it was not supported by the postmortem examination, and the blood-cells already described, although resembling those of leucocythemia, were larger and much more numerous than are generally the leucocytes, even in advanced splenic disease. How, then, is the condition of the blood to be accounted for? It is not expedient perhaps, in a scientific sense, to offer any explanation from a single case; but it is hoped rather that by placing it on record the attention of pathologists may be directed to a subject which does not yet appear to have received adequate investigation. Gibraltar.

Mr. George Fisher, M.B., C.M. Edin., a well known Scotch doctor, was found late on Sunday night lying dead on a sofa in his back shop at Millport, Island of Cumbrae. The cause of deathis as yet unknown.

\section{A CASE OF PUERPERAL CONVULSIONS, WITH COMPLICATIONS.}

BY W. TYRRELL BROOKS, M.B. LOND, PHISICIAN TO THE RADCLIFFE INFIRMARY, OXFORD.

ON Dec. 29th I was asked to see a case in consultation with Mr. Ballard of this town. The previous history was as follows. Mrs. T-, a young nervous woman, who had been under treatment at intervals for some years for neuralgia and other nervous affections, was expecting to be confined with her second child. On Dec. 19th she was seized with occasional convulsions, accompanied by pain and numbness of the right arm and leg, together with a slight dragging of the right leg in walking. The convulsions increased in severity until Dec. 22nd, when Mr. Ballard was sent for, who, finding the os uteri dilated and labour commenced, delivered the patient of a living child by instruments. After delivery the convulsions continued, but gradually became less severe. One convulsion occurred, however, of a much longer duration than the rest, after which the right side of the body was found to have become weaker than the corresponding side, and in a short time to have become completely paralysed. The convulsions after this became less frequent, and, instead of being general, were now limited to the upper part of the body. The last convulsion occurred on the sixth day after delivery. Ever since her confinement the patient had lain in a state of apathy, without speaking or taking notice of her surroundings. She, however, took readily a considerable quantity of liquid food, though she swallowed with a little difficulty. At first she passed her urine and fæces normally, but on the sixth day after delivery she began to pass them under her.

When I saw her on Dec. 29th she was lying in a state of unconsciousness. When spoken to sharply she endeavoured to put her tongue out, but failed. She followed my movements round the bed with her eyes, but would not follow the movements of my hand when asked to do so. The right leg and arm were completely paralysed, but had not lost sensation. On pricking the right arm or leg with a pin, she uttered a cry of pain, but did not speak, and drew away the corresponding member of the opposite side. Sensation on the left side was unimpaired. She expressed considerable pain when her right leg or arm was suddenly moved. The neck was extended and stiff, and any attempt to flex the head on the chest was resisted, the act being attended with considerable pain to the patient. The pupils were equal and reacted to light. There was not any evidence of facial paralysis. The pulse was 120 , tense and hard; the heart sounds normal ; respiration 36 , rapid and shallow. Over the whole of the upper lobe of the right lung there was bronchial breathing with fine expiratory crepitation. The lochia had continued for three or four days after confinement and then ceased. The tongue was coated and the teeth covered with sordes. The temperature was $101^{\circ}$.

When I saw her again on Dec. 31st there was considerable improvement in the general condition. She had spoken since my last visit, and appeared more sensible. The urine and fæces had been passed normally. The pulse was 120 , but much softer; temperature $99.5^{\circ}$; respiration 36 . Over the upper lobe of the right lung there was bronchial breathing with abundant crepitation. On Jan. 1st the improvement was still more marked. She answered questions slowly and hesitatingly, but her articulation was perfect. The breath sounds over the right pulmonary upper lobe were softer, and the crepitation still abundant. Respiration 30 ; pulse 120 ; temperature $99.5^{\circ}$. There was slight movement of the muscles of the upper part of the right arm and of the right leg. She complained of pain in the head, running down the back of the neck, and although the head could be flexed on the chest, it was accompanied by much pain, together with resistance of the cervical muscles.

On Jan. 4th the patient was practically convalescent. The respiratory sounds over the upper lobe of the right lung were almost vesicular, and the crepitation much diminished. The temperature was normal ; pulse 108; respiration 30 There was increased power in the right upper arm and leg, and also some movement of the left lower arm. The patient, though kept scrupulously clean by the nurse, had 
developed a bedsore. Since then the case has progressed favourably, and power has gradually returned to the paralysed side.

Remarks.-The case presents several points of interest. 1. The occurrence of puerperal convulsions, without the presence of albuminuria, in a neurotic patient, which continued for six days after delivery. 2. The supervention of right hemiplegia, which came on slowly after a very long convulsion, and in the course of a few days gradually disappeared. This was unaccompanied by facial paralysis, but was followed by the appearance of a bedsore. The gradual onset of and recovery from hemiplegia points, I think, to the occurrence of a small hæmorrhage in connexion with the internal capsule of the opposite side. 3. The presence of aphasia, which, although accompanied by right hemiplegia, I believe to have been functional. This was indicated by the aphasia having preceded the hemiplegia by two or three days, and also by the fact that the recovery of speech was sudden and complete. 4. The pneumonia, which was an extensive apical one, was of a low form, the highest temperature being $101^{\circ}$ In conclusion, I must thank Mr. Ballard for his kind assistance in the notes of the case, and for allowing me to see the patient during her convalescence.

\section{EXCISION OF THE ENTIRE UTERUS FOR CANCER.}

WITH NOTES OF A SUCCESSFUL OPERATION.

Br CHAS. E. JENNINGS, F.R.C.S. ENG., M.S., ASSTSTAVT-SURGEON TO THE CANCER AND NORTH-WEST LONDON HOSPITALS.

$$
\text { (Concluded from page 684.) }
$$

DR. WALLACE ${ }^{1}$ relates four cases of uterine excision. The first two were vaginal hysterectomies for early cancer, and both patients recovered. The last two were for advanced cancer; one operation was performed by the vaginal, the other by the abdominal, method, and both patients died. With regard to partial excision of the uterus, Dr. Wallace ${ }^{2}$ condemns the use of the ecraseur, as liable to be followed by hæmorrhage, and as dangerous to the peritoneum and adjacent organs; he also cites a case where it was followed by fatal shock, and therefore he discards the écraseur for amputation. For partial excision Dr. Wallace recommends anterior and posterior semilunar vaginal incisions. The uterine arteries and lower parts of the broad ligaments are to be ligatured at a distance of half an inch from the ureters, and the broad ligaments divided between the ligatures and the uterus. The cervix is to be dragged upon forcibly, and severed as high up as possible with scissors. The stump and flaps are to be washed with iodised water, the vaginal flaps being closed with sutures passed through the stump. Where difficulty is experienced in ligaturing the uterine vessels, Sir Spencer Wells's pressure-forceps are to be applied and left in situ for thirty-six or forty-eight hours. This operation is only to be advised for very early cancer.

Dr. Carl Schroeder considers it always possible to extirpate the entire uterus, even if wholly diseased. The adjacent parts of the vagina can also be removed, but this author questions the advisability of operating in such cases on account of probable recurrence. Where cancer of the cervical mucous membrane and of the body of the uterus exists there is always necessity for total extirpation. For extirpation of the uterus, Schroeder advises a circular vaginal incision to be made near the cervix, and Douglas's space to be opened. The fundus uteri (retroflexed) is to be drawn down with a volsellum. The broad ligaments are to be ligatured either singly or in separate portions. Whilst removing the uterus a great deal of tissue is to be left between the ligatures and the organ, otherwise the ligatures will slip. The wound in the peritoneum is to be closed, stitching the pedicles into the angles of the wound. A T -shaped drainage-tube is to be inserted and the end wrapped round with salicylated cotton, which must be renewed as often as it is soaked. The stitches are to be removed in fourteen days. Above all, the uterus must be well drawn down during the operation, a proceeding very difficult where the vagina is narrow and the uterus very much enlarged. Schroeder had seven deaths

1 Brit. Med. Jour., 1884, vol. ii., p. 1277.

2 Braithwaite's Retrospect, vol. Ixxxviif., p. 380 et seg. out of twenty-three cases of vaginal extirpation of the uterus. In his hands supra-vaginal excision gave a deathrate of eight out of sixty-four cases, but recurrence generally took place in those who survived the operation.

Professor Olshausen, ${ }^{3}$ in a letter to Sir Spencer Wells, recommended the employment of the elastic ligature for ligaturing the broad ligaments at a late stage of the operation. He employs a drainage-tube and iodoform gauze. The elastic ligatures are allowed to remain in situ for two or three weeks. Altogether Olshausen performed twenty-eight operations in two years and a half, three of which were supra-vaginal excisions; of these, all the patients recovered but one with a vesico-vaginal fistula. Out of the twenty-five cases of complete extirpation there were seven deaths-two on the day of operation, three of septicæmia on the second and third day, one of carbolic acid poisoning on the second day, and one of iodoform poisoning on the sixth day. Referring, however, to the last edition of Sir Spencer Wells's work, ${ }^{4}$ it appears that up to the end of 1884 Olshausen had thirty-four cases of complete vaginal extirpation, with seven deaths. Since there were seven deaths in the first twenty-five cases, it follows that the last nine operations must have been performed without a death, a circumstance which supports the view that diminishing mortality will accompany increasing operative experience of uterine excision. "Among the cases where there had been no reappearance of disease, two years have elapsed in two cases, in one case two years and a half, and in two cases three years; but in a larger proportion there has been reappearance in between one and two years." Olshausen emphasises the fact that the special danger of the operation is injury to the ureters, which appear to have escaped by stripping them up, together with the loose cellular tissue which surrounds the supra-vaginal portion, by means of the fingers.

On the other hand, a case is recorded in which M. Jules Boeckel of Strasburg ${ }^{5}$ dissected out the tissues between the uterus and bladder. A urinary fistula from injury to a ureter resulted, for which nephrectomy was performed, and the kidney removed was a healthy one. The patient recovered, left the hospital within six weeks of the first operation, and remained healthy, with the exception of polyuria, passing 1800 grammes of urine daily. She died in the seventh month, and a necropsy disclosed cancerous degeneration of the abdominal glands and parenchymatous inflammation of the remaining kidney.

A case is reported by Dr. Hennig (Leipsig) ${ }^{6}$ where the patient had survived vaginal extirpation eight months at the time of communication. There was then no recurrence. The steps of this operation were-(1) anterior vaginal incision; (2) separation by the fingers of the anterior fold of the peritoneum; (3) anteversion of the uterus and enucleation of the organ; (4) removal of a cancerous nodule from the rectum. The wound in the rectum was closed by sutures. The entire length of the uterus was five inches and a half, and the cervix was entirely invaded by the neoplasm. The left ovary and Fallopian tube were removed, also half the right Fallopian tube. Enucleation, without opening the peritoneum, had keen intended, but had not succeeded. Considerable peritonitis followed, but little hæmorrhage. A recto-vaginal fistula resulted, which was operated upon four weeks later. Four months afterwards a small recurrent nodule, which had arisen near the site of the fistula, was excised. There was no further recurrence.

Uterine excision by separation of the peritoneum was first proposed and successfully performed by Langenbeck. The woman survived the operation twenty-six years, but the uterus was not cancerous.

Dr. Gusserow, ${ }^{7}$ one of the latest writers on uterine extirpation, has collected 253 cases (where the operation was performed by the vaginal method), with a mortality of $23 \cdot 3$ per cent, the list including operations from the time of Sauter (1822), Blundell (1828), and Récamier (1829).

Pfannestiel collects 154 operations up to 1882 , with a mortality of 23 per cent.; but after 1882, thirty-six cases, with a mortality of only 8.3 per cent.

Gusserow advises the use of the curette and cautery as preliminary to making the vaginal and peritoneal incisions, so that when the uterus is retroflexed the chance of auto-

$$
3 \text { Ibid., p. } 392 .
$$

4 Diagnosis and Surgical Treatment of Abdominal Tumours, 1885 5 British Medical Journal, 1884, vol. i., p. 1262. THe LanCE'T, vol. i., 1877, p. 61 . 7 Deutsche Chirurgie, 1886, Lieferung 57. 